\title{
CORRESPONDENCE
}

\section{Always choosing the left for the subclavian venous cannulation?}

\author{
Jean-Rémi Lavillegrand ${ }^{1,2^{*}}$ (10) and Eric Maury ${ }^{1,2,3}$
}

(c) 2019 Springer-Verlag GmbH Germany, part of Springer Nature

\section{Dear Editor,}

We read with great interest the study comparing USguided cannulation of subclavian (SCV) and internal jugular (IJV) veins by Dr Shin et al. [1].

Whereas the main conclusion of the paper is that complication rates are similar at both sites, we think that several issues raised in this the paper should be addressed with caution.

First, the median access time for first attempt was very short in the two groups ( $5 \mathrm{~s}$ for IJV vs $15 \mathrm{~s}$ for SCV) and even statistically significant, the clinical relevance of this difference is questionable.

Second, while more catheter misplacements and arterial punctures were observed in the SVC group, the choice of the right site rather than the left for SCV cannulation may partially account for these differences. At the right SCV site, artery is more superficial and the route toward superior vena cava is less straightforward.

Indeed, Tarbiat et al. [2] observed that for SCV cannulation, the risk of misplacement was significantly higher on the right side than on the left side $(9.6 \%$ vs $0 \%$; $p=0.003$ ).

Furthermore, in an observational study including 1794 central venous subclavian catheterizations in ICU patients, fewer arterial punctures were observed when the left site was cannulated $(0.6 \%$ vs $3.7 \%)$ [3].

Finally, preferring the left side for SCV cannulation might be a simple method for limiting mechanical complications and catheter misplacement.

\begin{abstract}
Author details
${ }^{1}$ Service de Réanimation Médicale, Hôpital Saint-Antoine, Assistance Publique-Hôpitaux de Paris (AP-HP), 75571 Paris Cedex 12, France. ${ }^{2}$ Université Pierre-et-Marie Curie-Paris 6, Paris 6, France. ${ }^{3}$ Inserm U1136, 75012 Paris, France.
\end{abstract}

Compliance with ethical standards

\section{Conflicts of interest}

On behalf of all authors, the corresponding author declares no conflicts of interest.

\section{Publisher's Note}

Springer Nature remains neutral with regard to jurisdictional claims in published maps and institutional affiliations.

Accepted: 16 July 2019

Published online: 25 July 2019

\section{References}

1. Shin H-J, Na H-S, Koh W-U, Ro Y-J, Lee J-M, Choi Y-J et al (2019) Complications in internal jugular vs subclavian ultrasound-guided central venous catheterization: a comparative randomized trial. Intensive Care Med 4:968-976

2. Tarbiat M, Manafi B, Davoudi M (2014) Comparison of the complications between left side and right side subclavian vein catheter placement in patients undergoing coronary artery bypass graft surgery. J Cardiovas Thorac Res 6:147-153

3. Schummer W, Schummer C, Rose N, Niesen W-D, Sakka SG (2007) Mechanical complications and malpositions of central venous cannulations by experienced operators: a prospective study of 1794 catheterizations in critically ill patients. Intensive Care Med 33:1055-1059 